Atlas Journal of Biology, 2020, pp. 730-740

https://doi.org/10.5147/ajb.vi0.221

\title{
Over-Expression, Purification, and Characterization of Plant LeGST01, the Mammalian GST-Omega Homolog that Interacts with LeTPX1 from a Tomato cDNA Library
}

\author{
Khaled Sabarna ${ }^{1,2^{*}}$ and Firas Fohely ${ }^{1}$
}

${ }^{1}$ Faculty of Allied Medical Sciences, Palestine Ahliya University (PAU), Jabal Daher, P.O. Box 1041 Bethlehem, Palestine; ${ }^{2}$ Mediterranean Agronomic Institute of Chania (MAICh), Alsylio Agrokepiou, P.O. Box 85, GR-73100, Chania, Crete, Greece

Received: September 9, 2020 / Accepted: November 17, 2020

\begin{abstract}
The study focuses on an in vivo GST- omega homologue (pCRT7/TPxII intB4) over-expression, purification and characterization. Experiments purport to characterize the antioxidant activity of the LeTPx1, the interacting glutathione S-transferases BI-GST/GPx, LeGST-T1, T2, T3, T4, T5 and the mammalian inhibitor of apoptosis Bcl-2. Upon specific expression, the proteins exerted, differential protective effects in yeast cells treated with lethal doses of the prooxidants hydrogen peroxide, $t$-butyl hydroperoxide, and cumene hydroperoxide. The antioxidant activity of LeTPx1 was highest against the cumene hydroperoxide. The overexpressing GST (omega) homologue TPxintB4 (Baier and Dietz, 1999) which share a considerable homology of the mammalian GST-omega1. In conclusion, the work shows that yeast parental strains are extremely sensitive to very low concentrations $(0.2 \mathrm{mM})$ of Cumenehydroperoxide. However, after applying the different antioxidants; it appears that the smallest concentrations $t$ to be tolerated.
\end{abstract}

Keywords: LeTPx1, TPxintB4, over-expression, purification, cDNA library, GST (omega) homologue, hydrogen peroxide, tbutyl hydroperoxide, and cumene hydroperoxide, antioxidant activity.

"Corresponding author: firas@paluniv.edu.ps

ATLAS

This is an Open Access article distributed under the terms of the Creative Commons Attribution License (https://creativecommons.org/licenses/by/4.0), which permits unrestricted use, distribution, and reproduction in any medium, provided the original work is properly cited. 


\section{Introduction}

Oxidative stress reproduces different range of systemic appearance of reactive oxygen species (ROS). Living systems capability to freely detoxify the reactive intermediates or to restore the subsequent harm. Disorders in the standard redox state of cells can lead to toxic properties through the creation of peroxides and free radicals that damage all mechanisms of the cell, including macromolecules synthesis, and particularly DNA strand breaks. The destruction is mostly unintended and begins by reactive oxygen species (ROS) generated, e.g. $\mathrm{O}^{2-}$ (superoxide radical), $\mathrm{OH}$ (hydroxyl radical) and $\mathrm{H}_{2} \mathrm{O}_{2}$ (hydrogen peroxide) (Kala, 2015) Additionally, (ROS) act as cellular messengers in redox signaling. Therefore, oxidative stress can bring some disturbances in regular machineries of cellular signaling.

Production of reactive oxygen species is a predominantly damaging feature of oxidative stress. These active oxygen species consist of free radicals and peroxides. Some of the less reactive of these species (such as superoxide) can be converted by oxidoreduction reactions with transition metals or other redox cycling compounds (including quinones) into more aggressive radical species that can cause extensive cellular damage (Valko et al., 2005). Most long-term effects are caused by damage to DNA (Evans et al., 2004). DNA harm, made by ionizing radiation is comparable to oxidative stress, and these injuries have been concerned in cancer, aging and apoptosis. The vast majority of the oxygen-derived species are formed by typical laerobic metabolism. Regular cellular resistance mechanisms suppress most of them. Restoration of oxidative damages to DNA is non-stop, mostly synchronized with Non-renewable or a new induced injury. In the severe ranks of oxidative stress that cause necrosis, the damage causes ATP reduction, inhibiting organized apoptotic death and causing the cell to just collapse (Lelli et al., 1998).

An obvious result of aerobic metabolism is the creation of (ROS). In plants, ROS's are always made by the expected leak of electrons on $\mathrm{O} 2$ from the electron transference actions of mitochondria, chloroplasts, and plasma membranes or as a byproduct of several metabolic pathways localized in different cellular parts (del Rio, 2006; Blokhina and Fagerstedt, 2010; Heyno et al., 2011; Foyer et al., 1997). Environmental stresses such a metal toxicity, chilling, salinity, drought, and Ultraviolet radiation -B radiation in addition to pathogens attack lead to greater generation of ROS in plants due to disturbance of cellular homeostasis (Sharma et al., 2012; Hu et al., 2008; Mishra et al., 2011; Apel and Hirt 2004). The vast majority of ROS's are very damaging to plants at extraordinary concentrations. After the level of ROS go beyond the defense mechanisms, a cell is considered in a state of "oxidative stress." The greater manufacture of ROS through environmental stresses can posture a risk to cells by triggering oxidation of proteins, damage to nucleic acids, enzyme inhibition, peroxidation of lipids, activation of apoptosis leading to death of the cells (Verma and Dubey, 2003; Meriga et al., 2004; Maheshwari and Dubey, 2009).
Regardless of their damaging role, ROS are well-defined as second messengers in a diversity of cellular processes including tolerance to environmental stresses (Desikan, 2001; Yan et al., 2007). As a result of the multifunctional roles of ROS, it is essential for the cells to regulate the level of ROS firmly to escape any oxidative damage and not to remove them totally. Scavenging or clearing of additional ROS is attained by a well-organizedant oxidative system including the non-enzymatic in addition to enzymatic antioxidants (Noctor and Foyer, 1998). The enzymic antioxidants contain catalase (CAT), superoxide dismutase (SOD), enzymes of ascorbate-glutahione (AsAGSH) cycle such as ascorbate peroxidase (APX), monodehydroascorbate reductase (MDHAR), dehydroascorbate reductase (DHAR), and glutathione reductase (GR) (. Ascorbate (AsA), glutathione (GSH), guaiacol peroxidase (GPX), carotenoids, tocopherols, and phenolics (Noctor and Foyer, 1998) work as potent nonenzymic antioxidants inside the cell. Many scientists have reported that activities of various enzymes of the antioxidant protection system in plants to fight oxidative stress prompted by several environmental stresses. Conservation of a high antioxidant ability to scavenge the deadly ROS has been associated to enlarged tolerance of plants to previously mentioned environmental stresses. Substantial development has been achieved in improving stress-induced oxidative stress tolerance in plants by developed transgenic lines with improved levels of antioxidants (Faize et al., 2011). Immediate expression of many antioxidant enzymes has been exposed to be more active than single or double expression for emerging transgenic plants with improved tolerance to multiple environmental stresses (Lee et al., 2007). The newly characterized in vivo GST- omega homologue (pCRT7/TPxII intB4) appeared to be a promising antioxidant against oxidative stress and ROS systematic production in yeast.

\section{Genetic Background}

Strains: Escheribia coli, strain BL21(DE3)pLysS (INVITROGEN) one shot competent cells, This strain contains the lamda DE3 lysogen that carries the gene for T7 RNA polymerase under the control of the lacUV5 promoter. IPTG is required to induce expression of the T7 promoter.

Plasmids: plant GST (omega) pCRT7/TPxintB4

Primers for GST (omega) Homologue:

TPxintB4 '5-GAA TTC ATG GCT ACT CCA AGT GTA CAA- 3'

TPxintB4‘5-CTC GAG CGC CAA ATA TTT TTT CTT ATA TAA-3'

'5- ATC CAG CCT GAC TGG CTG AA -3' 


\section{Material and Methods}

\section{SDS-PAGE Electrophoresis}

Sodium dodecyl sulphate (SDS) is an anionic detergent, which denature protein by wrapping around, the polypeptide backbone and SDS binds to proteins fairly specifically. In by doing SDS confers a negative charge to the polypeptide. In denaturing SDS-PAGE separations therefore, migration is determined by molecular weight.

The resolving gel mixture was poured to the two glass plate sandwiches. This was immediately overlaid with water-saturated n-butanol to exclude oxygen from the surface. After polymerisation, the n-butanol was drained off and the gel surface rinsed with distilled water. Stacking gel should be overlaid on the resolving gel up to the brim of the glass plate sandwich. Are should be taken to avoid trapping any air bubble. A 10slot comb was inserted such that approximately ten $30 \mu \mathrm{l}$ wells were left on the stacking gel. The monomer was then left to polymerise. The polymerised gel slab-glass plates sandwich was removed from the casting stand and transferred to the buffer chamber, properly covered in buffer before the combs were carefully pulled out. Samples were then heated in boiling water for 7 minutes to denature the proteins then micro-centrifuged for $1 \mathrm{~min}$ at 12,000 rpm to avoid protein streaking during electrophoresis due to cell debris. Using a Prot/Elec loading tip, desired amounts of the protein samples or pre-stained SDSPAGE molecular weight standard markers were loaded into each lane. The gel run at a constant current at $40 \mathrm{~mA}$ per gel until the dye front reached the end of the gel.

\section{Gel Staining/Distaining}

Coomasoie brilliant blue staining solution was used to stain gels not made for western transfer and $\mathrm{SYPRO}^{\circledR}$ Ruby protein gel stain (Regular Marker). Gels were stained for 60 minutes and then destined in distaining solution till bands were clearly visible. All gels were then photographed.

\section{Western Blotting and Antibody Labeling of GST (omega)}

Western blotting involves transfer of electrophoretically separated components from a gel to solid support such as a nitro-cellulose, nylon and the Hybond PVDF membrane and probing with antibodies that react specifically with antigenic epitopes of specific sequence or tag of amino acids displayed by the target protein. Western blotting is extremely useful for identification and quantitation of a specific protein in complex mixture of proteins. Transfer efficiency however depends on many factors including gel concentration, thickness, protein size, shape and net charge and thus critical analysis for each individual case is of utmost importance before engaging on the transfer process. In general, power supply recommendations for wet western transfer apparatus are not supposed to exceed $350 \mathrm{~mA}$ and temperatures of the unit should remain below $10^{\circ} \mathrm{C}$ for 1-hour transfer. The GST -omega protein was expressed as $\mathrm{X}$-Press epitope tagged protein for antibody screening.

\section{Wet Western Transfer}

Two sheets of 3MM filter papers and one piece of the $\mathrm{Hy}$ bond PVDF membrane were cut to the size of the gel or a little bit bigger. The $3 \mathrm{MM}$ filter membranes were then soaked in transfer buffer and the Hybond PVDF membrane was activated in $100 \%$ methanol for 2 minutes then transferred into transfer buffer for 2-3 minutes. The gel was removed from the glass-plate sandwich, the stacking gel portion carefully removed and then equilibrated in transfer buffer for 5 minutes. Two gels were transferred at a time. The $3 \mathrm{MM}$ paper, Hybond PVDF membrane and the gel were then assembled on the Semidry transfer sandwich in the following order, Gel holder cassette, fiber pad, 3MM paper, the gel, Membrane, 3MM paper, Fiber pad, all air bubbles between membrane, gel and filter paper were removed by gently rolling a test tube over the surface after each individual addition of filter paper. Assemble the sandwich is assembled on the Electrode module in a way that the membrane will be proximal to the Cathode, in the Buffer tank. Carefully, the unit was connected to the power supply and the transfer run under a constant current of $350 \mathrm{~mA}$ for 60 minutes. Sterile Bar for distributing cool, and clean forceps was always used when handling membrane.

\section{Blocking and Antibody Labeling}

At the end of the transfer period, the unit was disassembled and the membrane briefly washed in $1 \mathrm{xTBS}$ to remove excess methanol and buffer reagents. It was then placed in a heat-sealable plastic bag with $10 \%$ non-fat dried milk blocking solution in $1 \mathrm{xTBS}$ at the rate of $0.1 \mathrm{ml}$ of blocking solution per square centimeter of membrane to mask potential nonspecific binding sites. Air bubbles were carefully removed as much as possible before the bag was sealed and left to gently shake for 3 hours at room temperature. The membrane was then washed twice in $0.1 \%$ Tween/1xTBS for 5 minutes and incubated with the primary antibody (Anti X-press) in $1 \%$ non-fat milk/1xTBS for at least three hours at room temperature or overnight at $4{ }^{\circ} \mathrm{C}$. In prior to the addition of the secondary antibody (HRP anti mouse), membrane was extensively washed with several quick changes of $0.1 \%$ Tween20/1xTBS. After 90 minutes in secondary antibody with shaking at room temperature, the membrane was extensively washed with quick changes of $0.1 \%$ Tween $20 / 1 x$ TBS for 1 hour.

\section{Developing the Blots}

The blots were developed using the peroxidase (HRP)-mediated chemiluminescent detection reagents (ECLTM Amer- 
sham). The detection solution was prepared by mixing equal volumes of solution 1 with solution 2 to yield sufficient volume to cover the membrane. The blot was then removed from the detection solution and excess solution was removed. The blot was enclosed in a plastic wrap while avoiding applying excess pressure as this could cause high backgrounds. The blot was placed, protein side up, into a film cassette making sure that no detection solution leaked out into the cassette. A fluorescence sticker was placed on one side of the cassette for orientation purposes of the developed film. In the dark room, the blot was exposed on an autoradiography film (Kodak) and the film cassette was tightly closed eliminating any possibility of light penetration for 1 minute. The film was then processed for 3-5 minutes in developing solution and then transferred to the fixing solution with a brief wash in water in between. The film was left in fixing solution till all background was faded away. Optimization of signal print intensity on the film was done by immediate preparation of additional exposures based on conclusions from the signals obtained initially.

\section{Colony Blot (The QIA Expressionist)}

The colony blot is used for the identification of clones expressing a 6xHis tagged protein, using the procedure anti His Antibody or Ni-NTA Conjugate. In many cases the antibody specific for the target protein was not available, as a result of over washing to avoiding non-specific signals.

\section{Small Scale Induction}

Positive colonies from the colony blot test were picked from the LB agar plates and inoculated into $5 \mathrm{ml} \mathrm{LB}$ medium containing $100 \mathrm{~g} / \mathrm{ml}$ ampicillin. Cultures were grown at $37^{\circ} \mathrm{C}$ with shaking until optical density was 0.5 . Adding a final concentration of $0.5 \mathrm{mM}$ IPTG induced expression of the protein. A duplicate set of the cultures was grown without induction, to serve as the un-induced control. The cultures were then grown for a further $6-\mathrm{h}$ at $30^{\circ} \mathrm{C}$. At the end of the induction, $1 \mathrm{ml}$ sample was collected from each culture and centrifuged at $13,000 \mathrm{rpm}$ for $2 \mathrm{~min}$. The supernatant was discarded and the pellet was re-suspended in $100 \mu \mathrm{L}$ of $2 \mathrm{x} \mathrm{SAB}$. The samples were stored at $-20^{\circ} \mathrm{C}$ until used.

\section{Large Scale Induction}

500-ml LB medium was prepared into 1-litre Erlenmeyer flasks, then autoclaved under standard conditions, then supplemented with $100 \mu \mathrm{g} / \mathrm{ampicillin}$ and $34 \mu \mathrm{g} / \mathrm{ml}$ Chloramphenicol final concentration. Cooling to around $37^{\circ} \mathrm{C} .5 \mathrm{ml}$ of an overnight E. coli culture containing pCRT7/TpxintB4 (plant GST-omega) was added and then incubated at $37^{\circ} \mathrm{C}$ with orbital shaking $(\sim 250 \mathrm{rpm})$. Culture was allowed to grow until (OD600 between 0.5-0.7). Induction was started by adding $0.5 \mathrm{MIPTG}$ from the $20 \%$ stock to the $500 \mathrm{ml}$ culture to a final concentration of $0.2 \%$. The cultures were then grown for an additional 9 hours at $30^{\circ} \mathrm{C}$. Bacterial cells were pelted by centrifugation at $4{ }^{\circ} \mathrm{C}$ in a Sorvall ${ }^{\circledR} \mathrm{RC} 24, \mathrm{GS}-3$ rotor (Dupont) for 7 minutes in large screw cup bottles. Pellets were re-suspended in lysis buffer for purification and dialysis. At this stage cells may keep in $-80^{\circ} \mathrm{C}$, or you can keep the pelt at $20^{\circ} \mathrm{C}$ before re-suspending it with the lysis buffer.

\section{Purification and Dialysis of Recombinant Plant GST-omega Homologue}

It is broadly recommended to empirically establish optimal conditions with small-scale cultures before purification on a large scale is attempted; since the culture conditions and the induction affect the production of the recombinant protein. Furthermore, each protein has its specificity interim of expression. As a result, the protocol for purification of GST (omega) as 6xHis-tagged proteins by Ni-NTA affinity chromatography of native soluble proteins described in the QIA expressionist TM handbook (1999) was employed with some modifications to increase the rate of purification. While the pellet of the induced cells chilled on ice, they were re-suspended with lysis buffer 5-ml/1gram pellet, 01mM PMSF was added to a final concentration of the lysate, $0.8 \mathrm{mg} \mathrm{Ly}-$ sozyme / $1 \mathrm{ml}$ lysate was added as well. The mixture was gently shaken for $20 \mathrm{~min}$ at room temperature, after sonication the lysate for 10- $15 \mathrm{~min}$ in ice, (the sonication and the pelleting should be repeated if the lyate is not clear enough). The lysate was centrifuged at 10,000 rpm for 30 minutes at $4^{\circ} \mathrm{C}$ Supernatant was collected and immediately placed on ice. A 1-ml aliquot was collected from the supernatant and saved at $4^{\circ} \mathrm{C}$ for SDS-PAGE and western blot if necessary. The remainder of the supernatant was mixed with $2 \mathrm{ml}$ of prewashed $50 \% \mathrm{Ni}-\mathrm{NTA}$ slurry per $500 \mathrm{ml}$ of cleared culture lysate and the mixture incubated gently shaking at $4^{\circ} \mathrm{C}$ for 1 hour. Washing of the Ni-NTA agarose beads slurry was done by adding $2 \mathrm{~mL}$ of well mixed $50 \% \mathrm{Ni}-\mathrm{NTA}$ to a falcon tube and centrifuging at 2,500rpm for 3 minutes, discarding the supernatant, then re-suspending the beads in equal volumes of Lysis buffer and centrifuging again.

The Ni-NTA-Lysate mixture was then loaded on an empty $10 \mathrm{ml}$ Ploy-Prep chromatography column to collect the flow-through collected and saved for SDS-PAGE and western blot analysis the rest was fast frozen by liquid nitrogen and kept in $-80{ }^{\circ} \mathrm{C}$. Washing was done with 6 column volumes of wash buffer supplemented with $0.1 \%$ TX-100 and the fractions kept for analysis on SDS-PAGE and western blot, the rest were fast frozen and kept in $-80^{\circ} \mathrm{C}$. Elution of the bound $6 \mathrm{x}-\mathrm{His}$ tagged-protein in $500-\mu \mathrm{l}$ elution buffers for four times in different microfuge tube. An aliquot was taken from each elution for SDS-PAGE, western blot, protein concentration, the remainder were stored with the same volume Glycerol for FPLC and enzyme activity analysis. To eliminate imidazole and the other detergent from the purified 
GST (omega), dialysis was performed. The protein was loaded into slide-A-Lyzer cassettes or dialysis bags if the volume of the protein stock is relatively high. The sample was applied on the dialysis cassettes using a syringe needle, and the cassette was subsequently immersed in continuously mixed $650 \mathrm{ml}-\mathrm{di}-$ alysis buffer. The buffer was changed twice and sample was dialyzed overnight.

\section{Estimation of Protein Concentration}

Total protein concentration for all samples was estimated by the method of Bradford (1976). This assay is based on the observation that the color of Coomassie Brilliant Blue G-250 (BIORAD) in dilute acid solution changes proportionally as the dye binds to protein. This is accompanied by a shift in absorbance maximum from $465 \mathrm{~nm}$ to $595 \mathrm{~nm}$. Standard samples of $0-25 \mu \mathrm{g}$ of BSA were prepared as dilutions of a BSA stock solution of $1 \mu \mathrm{g} / \mu 1$ to a total volume of $800 \mathrm{~mL}$ of distilled deionized water each. Seven standards with concentrations of $0,1,2,4,8,16$, and $25 \mu \mathrm{g}$ were prepared. To each, 200 $\mathrm{ml}$ of the Bio-Rad dye were added to make a final volume of $1 \mathrm{ml}$, well mixed and left to stand for at least 15 minutes and then their absorbance at $595 \mathrm{~nm}$ was measured on a diode array spectrophotometer (Hewlett Packard 8452A). Small aliquots of the collected samples with unknown protein concentration were prepared by (e.g., $10 \mathrm{ml}$ from each sample), mixed with $200 \mathrm{ml}$ of the Bradford dye and distilled H2Oto final volume $1 \mathrm{ml}$. After calculating the specific concentration (mg per unit volume). Normalized concentration of proteins was mixed with SDS-PAGE loading buffer. Once you have this, then it's easy to calculate how many micro-liters from each sample will give you a specified number of milligrams which you can set to be equal for all sample. This way you will have loaded the same amount of total protein $(\mu \mathrm{g})$ per well.

\section{Gel Filtration Chromatography (Size-Exclusion) (AKTA FPLC)}

Gel-Filtration chromatography separates proteins on the base of size. It measures the relative rates of passage through a molecular sieve (Polysaccharide gel in the shape of spherical beads). The technique is ideal for the final polishing steps in purification when the sample volume has been reduced. Buffer conditions are varied to suit the sample type or requirements for farther purification, for TPx and GST -omega we used a double filtrated $0.1 \mathrm{M} \mathrm{NaH} 2 \mathrm{PO} 4 \mathrm{pH} 7.5$, and with $20 \mathrm{mM}$ GSH and 0.1M DTT depending of the on the purpose of the run.

\section{Protein Re-Concentration (Centricon) Y-10}

Commercial centrifuging filter devices were used for the concentration and purification of Biological samples up to volume 0.5 and $2 \mathrm{ml}$.

\section{Dehydro-Ascorbate Reductase (DAR) Activity Assay}

The AHR activity of GSTO1 was measured in standard buffer $\mathrm{pH} 7,1 \mathrm{mMGSH}, 0.1 \mathrm{mM}$ bis-dehydroascorbate (bisDHA), by measuring the change in the absorbability of biDHA at standard nm, using an extinction co-efficient of $14700 \mathrm{M}-1 \mathrm{~cm}-1$.

\section{Results}

For small scale induction four 5-ml cultures of the above transformed cells were prepared, two of which were induced by $0.5 \mathrm{mM}$ IPTG while the other two were grown un-induced. 6 hours after the addition of the inducer, the cells were harvested, lysed and the cells extracts analyzed by SDS-PAGE. The presence of LeGSTO1 was confirmed by western blotting using the commercially available Anti X-press primary antibody (Kampranis et al. 2000). This recognizes an epitope, which is present in the $6 \mathrm{xH}$ is fusion protein, situated between the tag and the GSTO1 polypeptide.

For large-scale production of LeGSTO. Western blotting of the purified protein shows two bands of molecular weight close to $35 \mathrm{kDa}$. The predicted size of LeGSTO1 (including

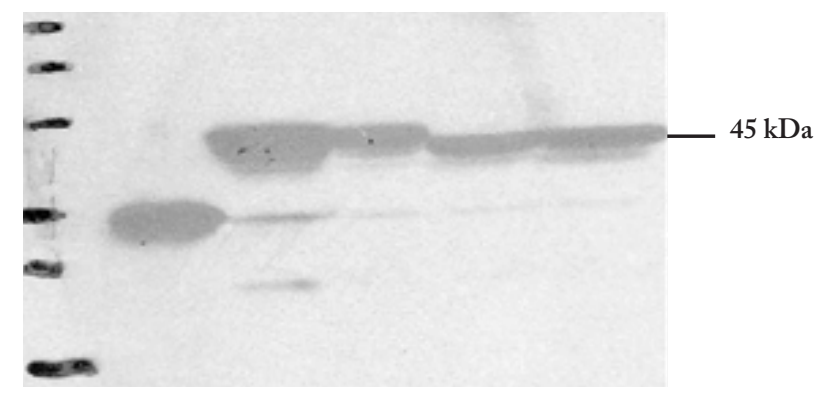

Figure 1. Deletion of plant GST-omega homologue expression from bacterial extracts using anti $\mathrm{X}$ press epitope anti bodies.

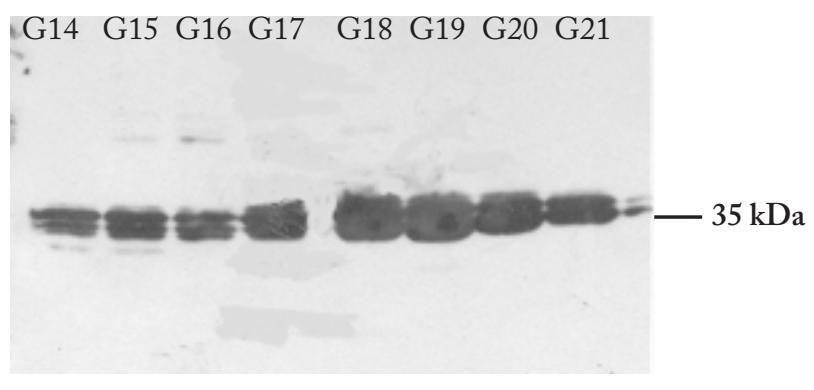

Figure 2. Anti X press Labeled Western Blot Purified GST (omega) Elution 2 Fractions from left to right G14 $\rightarrow$ G21. 
the fused tag) is approximately $31 \mathrm{kDa}$. Higher apparent size on SDS-PAGE gels indicates that this protein exhibits anomalous mobility in these conditions. GST Omega (GSTO1) original construct were sequenced, analyzed by specific restriction enzymes (Data not shown) The recombinant human GSTO1 was also found to have anomalous mobility on SDSPAGE gels.(Kampranis et al. 2000). The presence of two distinct bands on western blots is probably due to the protolytic cleavage of the $\mathrm{C}$-terminus of the fusion protein during protein induction or purification (Figure 2).

\section{Dehydro-ascorbate Reductase (DAR) Activity}

The human homologue of LeGSTO1 has shown to exhibit thiol-transferase and dehydro-ascorbate reductase (DAR) activity in this paper. We tested LeGSTO1 for its ability to catalyze the reduction of dehydro-ascorbate. The specific activity of the purified recombinant plant-enzyme was found to be $0.059 \mathrm{U} / \mathrm{mg}$, in good agreement with the activity of the human enzyme, which was reported (22) to be $0.16 \mathrm{U} / \mathrm{mg}$ (Figure 3).

LeGSTO1 was isolated as an inter-actor to LeTPx, by the means of a yeast two-hybrid assay (13). To study the molecular details of this interaction, recombinant purified proteins were used for in vitro experiments. LeTPx was found to interact with GSH, since its presence could protect the protein from trypsin degradation. This protection could be reversed by the inclusion of LeGSTO1 in the reaction, suggesting an interaction between LeGSTO1 and LeTPx.

The interaction between these two proteins was investigated further using gel-filtration chromatography. LeTPx was found to be a strong dimer in solution, having a complex mo-

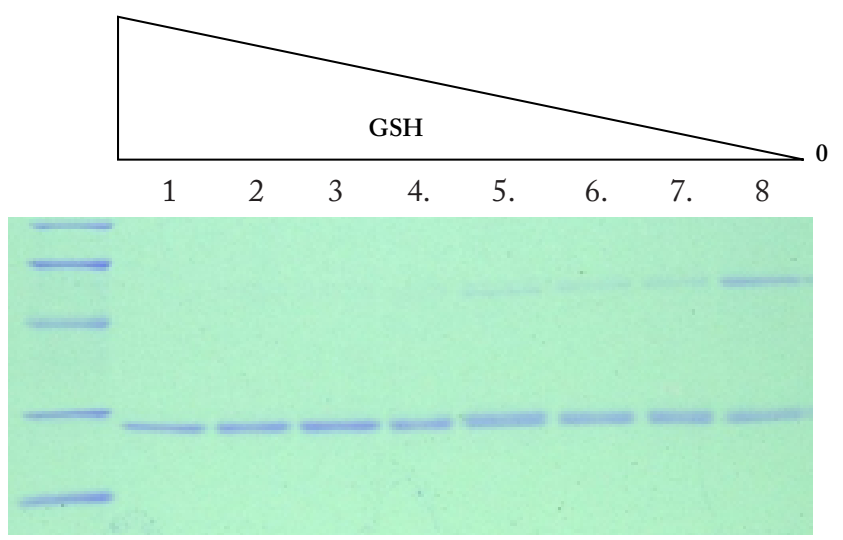

Figure 3. Titration of GSH to investigate the effect of GSH on the removal of the dimerized TPx band. The lanes from left to right 1) $0.088 \mathrm{mg} / \mathrm{ml}$ TPx $+1 \mathrm{mM}$ GSH, 2) $0.088 \mathrm{mg} / \mathrm{ml}$ TPx $+0.6 \mathrm{mM}$ GSH, 3) $0.088 \mathrm{mg} / \mathrm{ml} \mathrm{TPx}+0.3 \mathrm{mM}$ GSH, 4) $0.088 \mathrm{mg} / \mathrm{ml} \mathrm{TPx}+0.1 \mathrm{mM} \mathrm{GSH}$, 5) $0.088 \mathrm{mg} / \mathrm{ml} \mathrm{TPx}+0.06 \mathrm{~mm} \mathrm{GSH}$, 6) $0.088 \mathrm{mg} / \mathrm{ml} \mathrm{TPx}+0.03 \mathrm{mM}$ GSH, 7) $0.088 \mathrm{mg} / \mathrm{ml} \mathrm{TPx}+0.01 \mathrm{mM}$ GSH, 8) $0.088 \mathrm{mg} / \mathrm{ml} \mathrm{TPx}$.

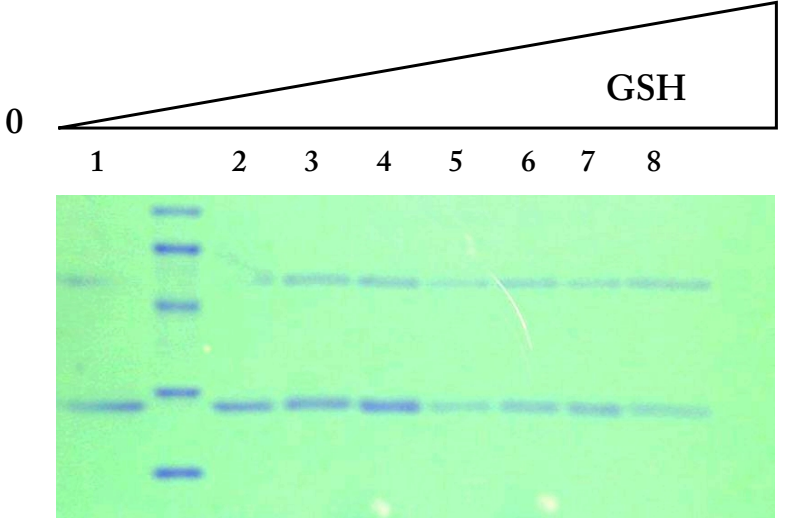

Figure 4. Titration of the oxidized form of GSH (GSSG) to investigate the effect of GSSG on the removal of the dimerized TPx. The lanes from left to right 1) $0.088 \mathrm{mg} / \mathrm{ml} \mathrm{TPx}$, 2) $0.088 \mathrm{mg} / \mathrm{ml} \mathrm{TPx}+0.005 \mathrm{mM}$ GSSG, 3) $0.088 \mathrm{mg} / \mathrm{mlTPx}+0.015 \mathrm{mM}$ GSSG, 4) $0.088 \mathrm{mg} / \mathrm{ml} \mathrm{TPx}+0.03 \mathrm{mM}$ GSSG, 5) $0.088 \mathrm{mg} / \mathrm{ml}$ TPx + $0.05 \mathrm{~mm}$ GSSG, 6) $0.088 \mathrm{mg} / \mathrm{ml}$ TPx + $0.15 \mathrm{~mm}$ GSSG, 7) $0.088 \mathrm{mg} / \mathrm{ml}$ TPx + $0.3 \mathrm{~mm}$ GSSG 8) $0.088 \mathrm{mg} / \mathrm{ml}$ TPx $+6 \mu 10.5 \mathrm{mM}$ GSSG.

lecular weight of $\sim 45 \mathrm{kDa}$. This dimer was stable both at reducing (DTT) and high ionic strength conditions. LeGSTO1 was found to give rise to two peaks, one representing the monomer and one representing the dimer. When the protein contained in the fraction corresponding to the monomeric form was reapplied to the column, again two peaks were observed, suggesting the existence of a monomer dimmer equilibrium for LeGSTO1. The monomer: dimer ratio was only fractionally dependent on DTT, indicating an interaction not significantly dependent on the presence of inter-subunit disulfide bonds (data not shown).

When the two proteins were mixed together, no additional peak indicating hetero-tetramer or any other multisubunit association was observed. The inability of the two proteins to show a stable interaction in these experiments suggests the existence of a transient interaction between the two molecules. This is not stable enough to support the appearance of a clear peak in gel-filtration. LeTPx belongs to the family of type $\mathrm{C}$ plant peroxiredoxin: these proteins reduce hydrogen peroxide or alkylhydroperoxides in the expense of an intersubunit disulfide bond. This bond is then reduced by thioredoxin, which transfers the oxidation equivalents to NADPH through NADPH-dependent thioredoxin reductase. When LeTPx is isolated from bacteria and run on SDS-PAGE gels in the absence of $\beta$-mercaptoethanol, two distinct bands are evident (Figure 2). One corresponding to the mono-meric form and one to the di-meric. The dimer has its active site cysteines linked with a disulfide bond. This is a result of oxidation of the enzyme during purification. Addition of DTT or $\beta$ mercaptoethanol results in the disappearance of the dimer band. When LeTPx is incubated with GSH and analyzed by non-reducing SDS-PAGE, the dimmer band disappears. It is clear that the observed interaction of LeTPx with GSH re- 


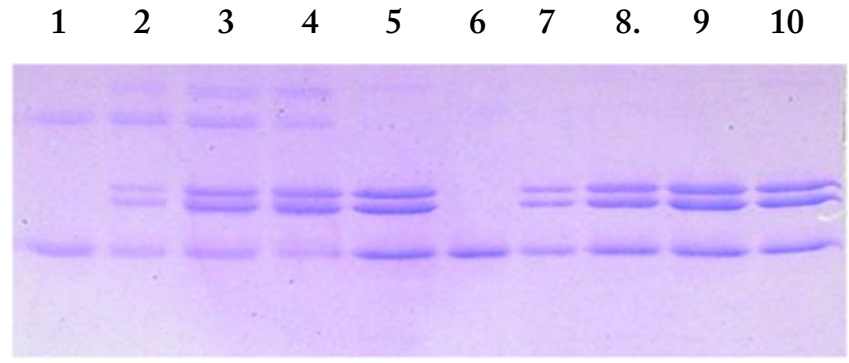

Figure 5. Investigating the dimerization of TPx in the presence of highly purified GST-Omega and the effect of 20mM GSH and 0.1mMDTT. The lanes from left to right 1) $0.088 \mathrm{mg} / \mathrm{ml} \mathrm{TPx}$, 2) $0.088 \mathrm{mg} / \mathrm{ml} \mathrm{TPx}+$ $0.028 \mathrm{mg} / \mathrm{ml}$ GST-Omega, 3) $0.088 \mathrm{mg} / \mathrm{ml} \mathrm{TPx}+0.07 \mathrm{mg} / \mathrm{ml} \mathrm{GST-Omega}$ 4) $0.088 \mathrm{mg} / \mathrm{ml} \mathrm{TPx}+0.098$ GST-Omega, 5) $0.088 \mathrm{mg} / \mathrm{ml} \mathrm{TPx}+0.098 \mathrm{mg} / \mathrm{ml}$ GST-Omega +0.01mM DTT, 6) $0.088 \mathrm{mg} / \mathrm{ml} \mathrm{TPx}+0.8 \mathrm{mM}$ GSH, 7) $0.088 \mathrm{mg} / \mathrm{ml}$ TPx $+0.028 \mathrm{mg} / \mathrm{ml}$ GST-Omega $+0.8 \mathrm{mMGSH}, 8)$ $0.088 \mathrm{mg} / \mathrm{ml} \mathrm{TPx}+0.07 \mathrm{mg} / \mathrm{ml}$ GST-Omega $0.8 \mathrm{mM}$ GSH, 9) $0.088 \mathrm{mg} / \mathrm{ml}$ TPx + 0.098 GST-Omega $+0.8 \mathrm{mM}$ GSH, 10) $0.088 \mathrm{mg} / \mathrm{ml} \mathrm{TPx}+$ $0.098 \mathrm{mg} / \mathrm{ml}$ GST-Omega+ 0.8mM GSH+ 0.01mMDTT.

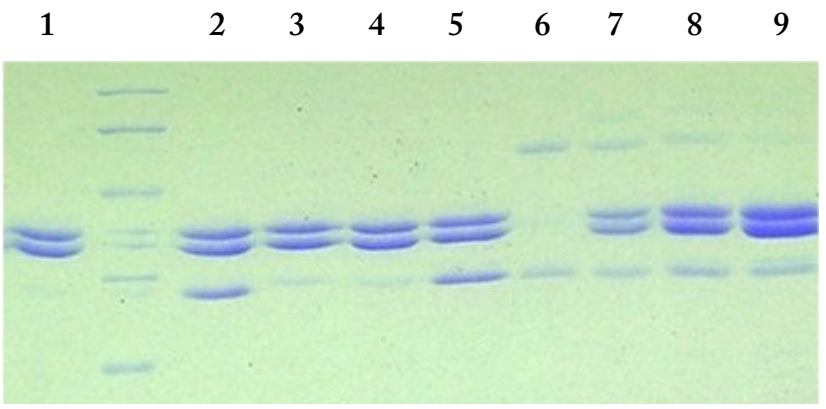

Figure 6. TPx and GST-Omega dimerization in the presence of DDT. Lanes from left to right 1) $0.07 \mathrm{mg} / \mathrm{ml} \mathrm{GST-Omega,} \mathrm{2)} 0.07 \mathrm{mg} / \mathrm{ml} \mathrm{GST-}$ Omega $+0.088 \mathrm{mg} / \mathrm{ml} \mathrm{TPx}$ 3) $0.07 \mathrm{mg} / \mathrm{ml}$ GST-Omega +0.01mMDTT), 4) $0.07 \mathrm{mg} / \mathrm{ml} \mathrm{GST-Omega+} 1 \mathrm{mM}$ GSH 5) $0.07 \mathrm{mg} / \mathrm{ml} \mathrm{GST-Omega} \mathrm{+}$ $1 \mathrm{mM} \mathrm{GSH}+0.088 \mathrm{mg} / \mathrm{ml} \mathrm{TPx}, 6) 0.088 \mathrm{mg} / \mathrm{ml} \mathrm{TPx},(7) 0.042 \mathrm{mg} / \mathrm{ml}$ GST-Omega $+0.088 \mathrm{mg} / \mathrm{ml}$ TPx, 8) $0.084 \mathrm{mg} / \mathrm{ml}$ GST-Omega + $0.088 \mathrm{mg} / \mathrm{ml}$ TPx, 9) $0.161 \mathrm{mg} / \mathrm{ml}$ GST-Omega $+0.088 \mathrm{mg} / \mathrm{ml}$ TPx.0.098mg/ml GST-Omega+ 0.8mM GSH+ 0.01mMDTT.

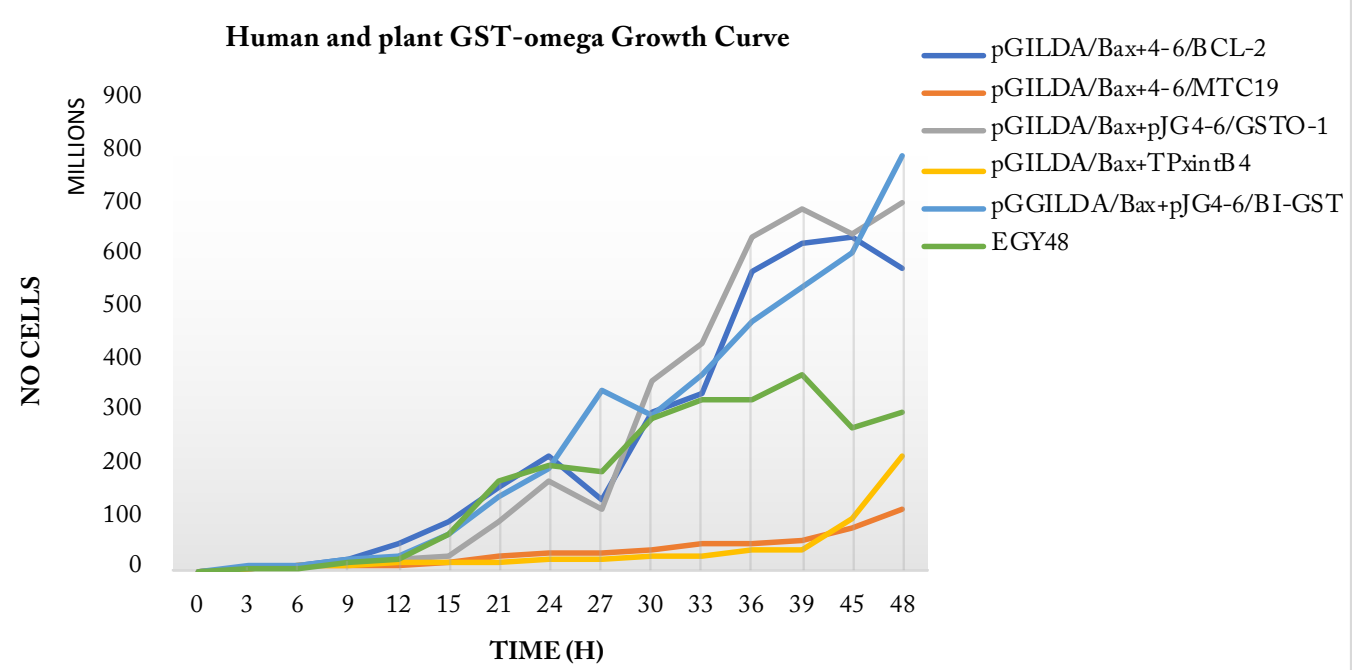

Figure 7. Expression of different antioxidant proteins partially inhibit Bax lethality in yeast and restore the mitochondrial membrane potential $\Delta \Psi_{\mathrm{m}}$. EGY48 cells expressing the LexA-Bax protein with each of the different antioxidants were grown in liquid cultures containing galactose as carbon source to induce proteinexpression.

sults in the reduction of the inter-molecular disulfide bond. In figure. 3 the effect of increasing concentrations of GSH on disulfide bond formation is studied. At concentrations higher than $0.03 \mathrm{~mm}$, GSH completely abolishes disulfide bond (see Figure.3). Oxidized glutathione (GSSG) failed to break the disulfide bond of TPx at any concentration (Figure 4).

When increasing concentrations of LeGSTO1 and directly incubated with LeTPx, breakage of the inter-subunit (see Figure 5). Disulfide of the LeTPx was also observed with a concomitant formation of LeGSTO1 high order crosslinked species. This suggests that the interaction of LeTPx with LeGSTO1 leads to the reduction of the former in expense of a disulfide bond on the latter (Figure 6).

\section{Assessing the Potential of the GST-omega Homology to Inbibit Bax Lethality}

As shown in Figure 7, expression of BI-GST/GPx, Bcl2 and human GST-GST-Omega1 inhibit Bax lethality. Expression of the plant homologous protein does not inhibit the lethality phenotype caused by Bax in contrast with all the other characterized LeGST's that are at least partial inhibitors of the Bax phenotype.

To assess the ability of the LeTPx1 and the LeGST interacting proteins to function antioxidant molecules, we evaluated their ability to enhance survival to oxidative stress induced cell death by $\mathrm{H}_{2} \mathrm{O}_{2}$ (see Figure 8) and the lipid soluble organic hydro peroxides, tert-Butyl hydroperoxide ( $t$ - 


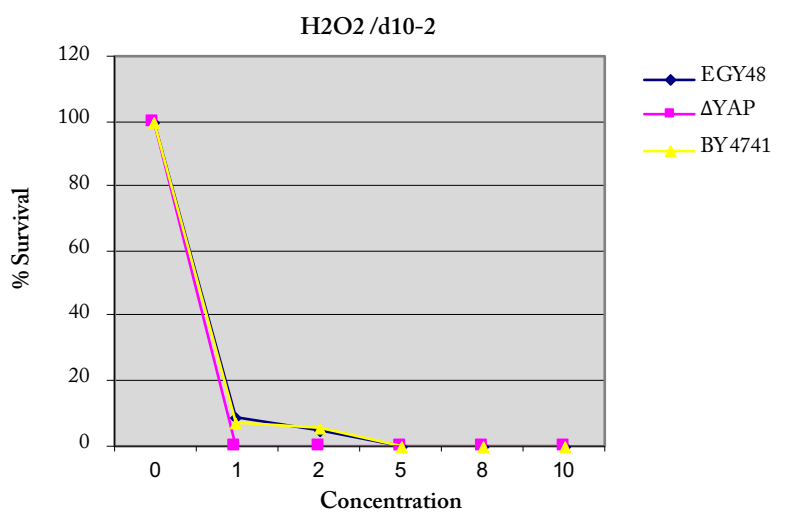

Figure 8. Survival assays of EGY48 yeast cells against hydrogen peroxide. Freshly grown EGY48, $\triangle$ YAP, and BY4741 parental strains on galraff/CM against $1 \mathrm{~N} \mathrm{H}_{2} \mathrm{O}_{2}$ lethality on YPD plates.

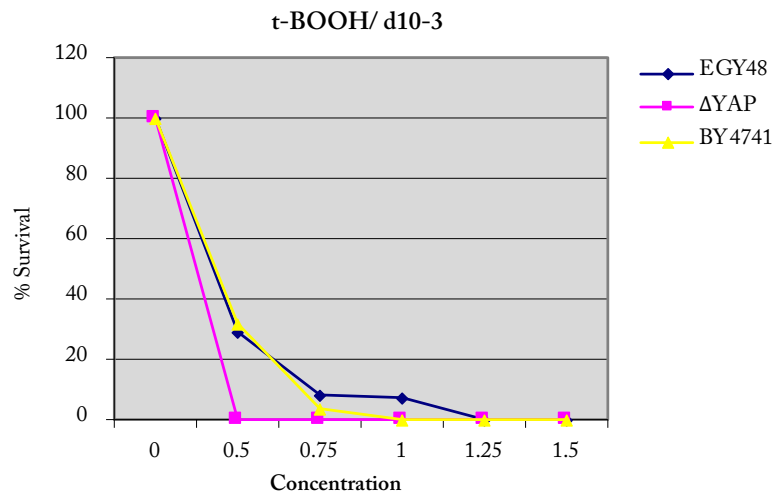

Figure 9. Survival assays of EGY48 yeast cells against tert-butyl hydroperoxide. Freshly grown EGY48, $\triangle$ YAP, and BY4741 parental on galraff/CM strains against $100 \mathrm{mM}$ t-BOOH lethality on YPD plates.

$\mathrm{t}-\mathrm{BOOH} \mathrm{d} 10-2$
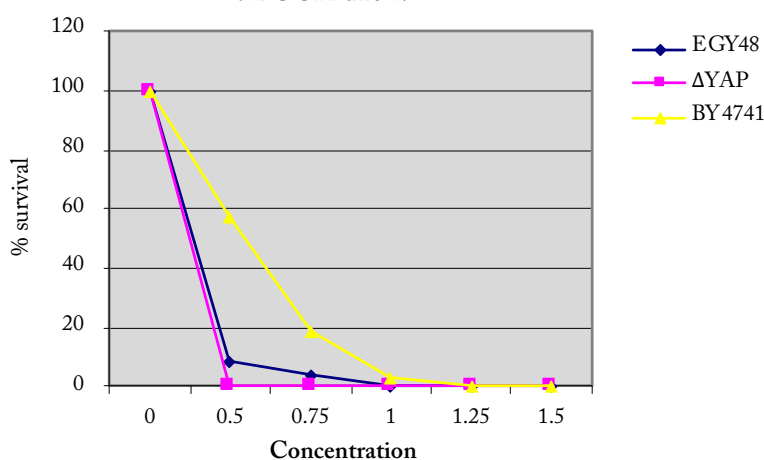

Figure 10. Survival assays of EGY48 yeast cells against cumenehydroperoxide. Freshly grown EGY48, $\triangle$ YAP, and BY4741 parental strains on gal-raff/CM show completely negative growth against $100 \mathrm{mM} \mathrm{Cu}-$ menehydroperoxide on YPD plates.
$4.5 \mathrm{mM} \mathrm{H} 2 \mathrm{O} 2 / \mathrm{d} 10-2$

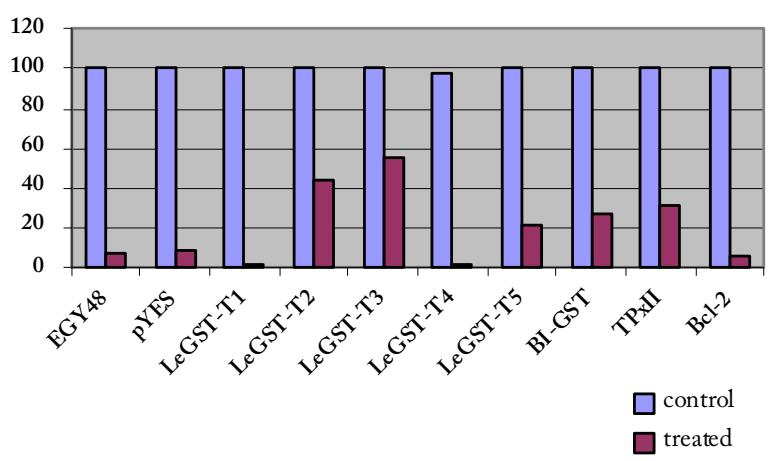

Figure 11. The LeGSTs, LeTPx1 and Bcl-2 exhibit differential protective effect against $\mathrm{H}_{2} \mathrm{O}_{2}$ freshly grown EGY48 cells expressing LeGSTs, LeTPx1 and Bcl-2 were diluted to OD600 and treated with $4.5 \mathrm{mM}$ $\mathrm{H}_{2} \mathrm{O}_{2}$.

\section{$1.25 \mathrm{mM}$ t-BOOH$/ \mathrm{d} 10-2$}

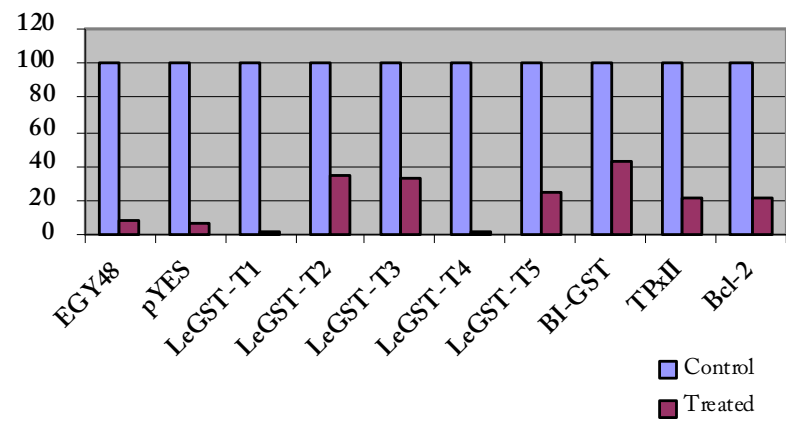

Figure 12. The LeGSTs, LeTPx1 and Bcl-2 exhibit differential protective effect against t-BOOH freshly grown EGY48 cells expressing LeGSTs, LeTPx1 and Bcl-2 were diluted to OD600 and treated with $1.25 \mathrm{mM}$ t-BOOH.

$0.2 \mathrm{mM}$ Cumene Hydroperoxide/d10-2

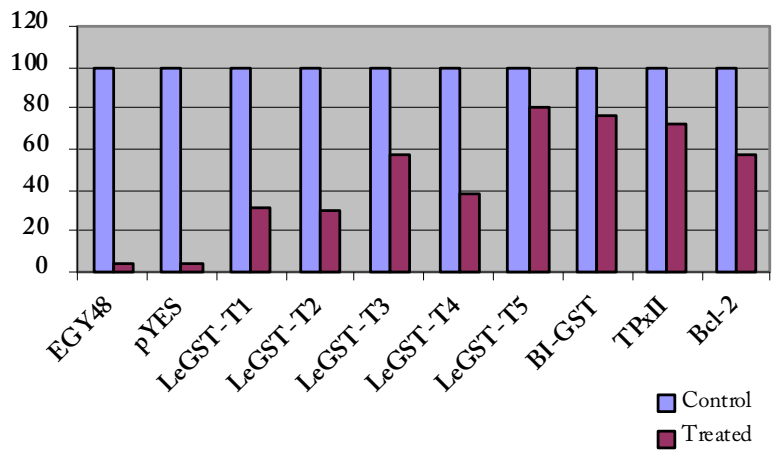

Figure 13. The LeGSTs, LeTPx1 and Bcl-2 exhibit differential protective effect against CHP freshly grown EGY48 cells expressing LeGSTs, LeTPx1 and Bcl-2 were diluted to OD600 and treated with $0.2 \mathrm{mM}$ CHP, LeTPx1 and Bcl-2 were diluted to OD600 and treated with $1.25 \mathrm{mM} \mathrm{t}-\mathrm{BOOH}$ 


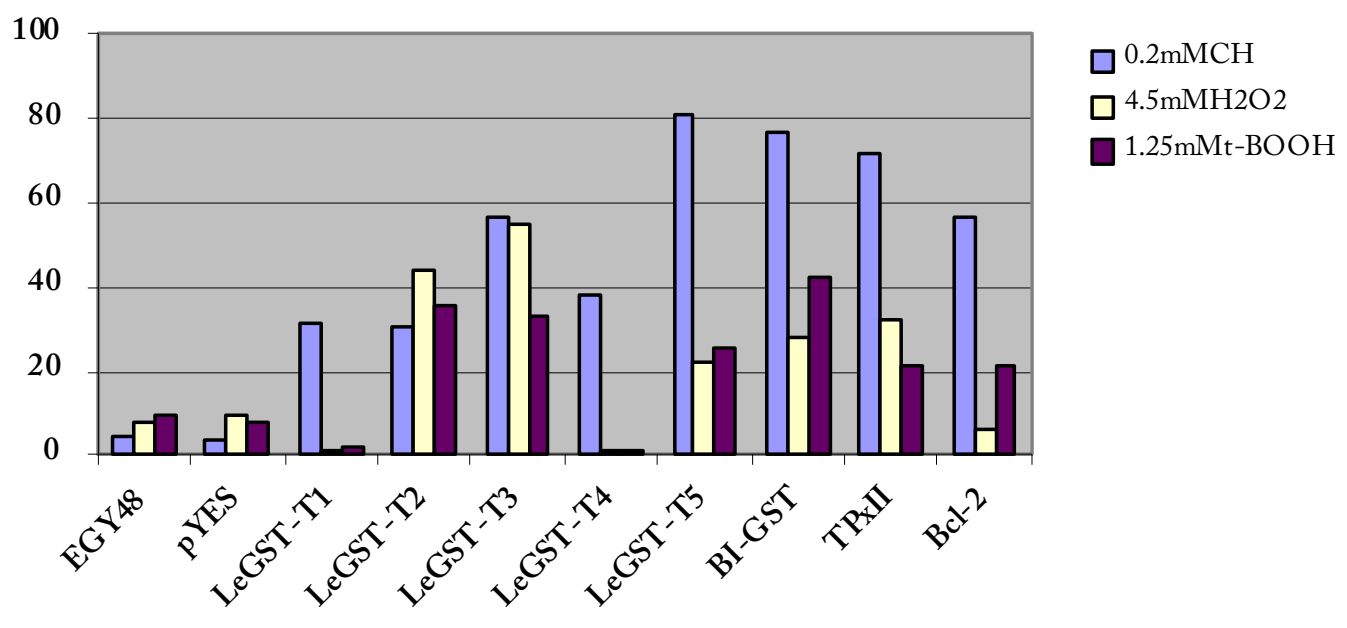

Figure 14. The activity of each antioxidant toward the lethality of $0.2 \mathrm{mM}$ Cumenehydroperoxide, $4.5 \mathrm{mMH}_{2} \mathrm{O}_{2}$, and $1.25 \mathrm{mMt}-\mathrm{BOOH}$ prooxidants is variable.

$\mathrm{BOOH})$ (see Figure 9) and cumene hydroperoxide (CHP). (see Figure 10). Survival assays were initially established to determine the minimum concentration and length of exposure to prooxidants that kills at least $90 \%$ cells for three yeast strains.

As shown in Figure 11, expression of the LeGST proteins protected yeast cells from $\mathrm{H}_{2} \mathrm{O}_{2}$-induced oxidative stress to varying degrees ranging from complete absence of protection for LeGST-T1 and LeGST-T4 to very high levels from LeGST-T2 (45\%) and LeGST-T3 (51\%). BI-GST/GPx was the third most protective protein among the LeGST proteins conferring $31 \%$ survival to the cells. TPxII (32\%) show almost the same activity of BI-GST, meanwhile Bcl-2 (6.6\%) appeared as a non-active antioxidant against $4.5 \mathrm{mM} \mathrm{H}_{2} \mathrm{O}_{2}$.

The behavior of the proteins against the organic hydroperoxide was dramatically different from that against $\mathrm{H}_{2} \mathrm{O}_{2}$. All the tested proteins were more potent in inhibiting cell death the lipid soluble hydro-peroxides. The most potent LeGST inhibitors were LeGST-T5 (80\% survival for $\mathrm{t}-\mathrm{BOOH}$ and CHP) and BI-GST/GPx (approximately 75 for $\mathrm{t}-\mathrm{BOOH}$ and CHP) (Figure 12).

LeGST-T1 and LeGST-T4 also exhibited antioxidant activity. In the case of LeGST-T4 its protective effect reached $38 \%$ for CHP treatment. Unexpectedly, Bcl-2 and TPxII turned to be very active against the organic hydroperoxide (approximately $57 \%$ for $\mathrm{Bcl}-2$ against $\mathrm{CHP}$, and $72 \%$ for TPxII against t-BOOH) (Figure 13).

In the case of the antioxidant behavior of the LeGST molecules, it is interesting to note that even though they belong to the same family of type III (Tau) GSTs, they exhibit widely varying capacities with different pro-oxidant compounds, suggesting a specialization inside plant cells to cope with ROS and environmental injury (Figure 14).

\section{Conclusion}

The implementing of the Two-Hybrid genomic screen afforded us with 26 proteins (Kampranis et al., 2000) that interact with LeTPx1.Our focus was on the over-expression and characterization of GST- omega homologue LeGSTO (Baier and Dietz, 1999) due to its significant biological and medical effects. Dissimilar to other GST omega's classes it appears to have an active site cysteine that can form a disulfide bond with glutathione (Kampranis et al., 2000). The biochemical properties of these proteins were analyzed in vitro. LeGSTO1 was found to have dehydro-ascorbate reductase activity like its human equivalent. Remarkably, LeGSTO1 was found to be capable of reducingan inter-subunit disulfide present in the oxidized form of LeTPx1. The plant GSTO1 homologue was also tested for its capability to prevent the Bax lethal phenotype in yeast. The plant homologue in difference with its mammalian counterpart did not suppress the Bax phenotype. A characterization for the capability of LeTPx1 and GSTomega to terminate Bax lethality, characterization was performed as well. Expression of the plant homologous to GSTO1 protein does not avoid the lethality phenotype created by Bax, in difference with the human GST-omega that is an inhibitor of the Bax phenotype. It is well wellknown that Bax protein is assumed to decline the intracellular levels of entire glutathione, reduce the mitochondrial potential and adjust organelle utility by confining to the outer mitochondrial membrane and creating an ion passage. So as to estimate the protecting consequence conferred by the recently isolated LeTPx1, Bcl-2, and the Le GSTs proteins to cells under oxidative stress, the aptitude of cells to survive was evaluated by establishment of in vivo survival analyzes. Hydrogen 
peroxide, tert-butyl hydroperoxide, and cumene hydroperoxide prooxidants afford reactive oxygen types that can react with a multiplicity of biomolecules, changing or blocking their biological exploit. The focuses of the used prooxidants characterize the slight concentration and interval of exposure that causes above $95 \%$ death in EGY48 control cells. In these tests, it was exposed that expression of the LeGST proteins protected yeast cells from $\mathrm{H}_{2} \mathrm{O}_{2}$-induced oxidative stress to variable amounts fluctuating from whole nonappearance of protection for LeGST-T1 and GST-T4 to actual high altitudes from LeGST-T2 and LeGST-T3.TPxII and BI-GST display almost a similar activity; in the meantime, Blc-2 seemed not to be vigorous antioxidant. For the lipid soluble hydroperoxide, the most powerful LeGST inhibitors were LeGST-T5 and BI-GST/GPx. TPxII and Bcl-2 exhibited important antioxidant activity against organic hydroperoxide. GST-Omega homologue interactor, was expressed in E. coli and purified for additional characterization. Purified Le GSTO1 displayed two separate bands of approximately 35 $\mathrm{kDa}$ on SDS-PAGE gels and western blots. The two distinct bands possibly result of protcolytic cleavage of this protein through expression in bacteria. Like its human complement, LeGSTO1 exhibited dehydro ascorbate reductase activity. The precise activity of the tomato enzyme was $0,059 \mathrm{U} / \mathrm{mg}$, which is comparable to the activity of the humanoid enzyme.

For the gel-filtration experiments, LeGSTO1 was probably shaped to be both in the monomeric and dimeric arrangement. This proposes that the tomato enzyme is pathetic dimer in solution in dissimilarity to the human enzyme, which is found mainly in the dimer form. Gel-filtration experimentations unsuccessful to display any solid link between LeGSTO1 and LeTPx1. Thus, the contact between these two proteins that was noticed in the yeast two-hybrid assay is possibly a temporary. However, this interaction looks to be physiologically related, since LeGSTO1 is capable of reducing the oxidized form of LeTPx1, as is demonstrated by the reduction of an inter subunit disulfide bridge in LeTPx1 by the action of LeGSTO1.

All the tested antioxidants even for the weakest. (LeGSTT1(31.65\%), and LeGST-T4 (37.93\%) which show great deal of toxicity for yeast cells with $\mathrm{H}_{2} \mathrm{O}_{2}$ and t-BOOH. Similarly, Bcl-2 shows no activity toward $\mathrm{H}_{2} \mathrm{O}_{2}$ whereas it shows a considerable activity toward $\mathrm{t}-\mathrm{BOOH}$, and one of the most active antioxidants against Cumene hydroperoxide (see Figure 14). These results strongly indicate the high specificity of each antioxidant to the same substrate, in other words, more than one pathway or mechanism could be available for the same antioxidant independent adaptation to the generated ROS. Many factors could be interacting, such as the intensity of the ROS, the mechanism of oxygen activation, the structure of yeast membranes or organelles, and the presence of some enzymes or factors that could suppress one pathway and initiate the other. This indicates that it is not the hydroperoxide moiety, that induces the adaptive response, and also that the yeast cells had specifically adapted to Loom. Considerable work needed to be done in this direction to elucidate these mechanisms and the protein complex interactions responsible for them.

\section{Conflict of Interest}

The authors declare no conflict of interest in preparing this article, the authors also declare that this research received no specific grant from any funding agency in the public, commercial, or not-for-profit sectors.

\section{Acknowledgments}

The Authors would like to sincerely thank all the parties that collaborate in this work.

\section{References}

Apel K and H Hirt (2004) Reactive oxygen species: Metabolism, oxidative stress, and signal transduction. Annual Review of Plant Biology 55: 373-399. https://doi.org/10.1146/annurev.arplant.55.031903.141701.

Baier M and KJ Dietz (1999) Protective function of chloroplast 2cysteine peroxiredoxin in photosynthesis. Evidence from transgenic Arabidopsis. Plant Physiology 119: 1407-1414. http://doi.org/10.1104/pp.119.4.1407.

Blokhina $\mathrm{O}$ and KV Fagerstedt (2010) Oxidative metabolism, ROS and $\mathrm{NO}$ under oxygen deprivation. Plant Physiology and Biochemistry 48 (5): 359-373. doi:10.1016/j.plaphy.2010.01.007.

del Rio LA (2006) Reactive Oxygen Species and Reactive Nitrogen Species in Peroxisomes. Production, Scavenging, and Role in Cell Signaling. Plant Physiology. http://doi.org/10.1104/pp.106.078204.

Desikan R, SAHM Mackerness, JT Hancock, and SJ Neill (2001) Regulation of the Arabidopsis Transcriptome by oxidative stress. Plant Physiology. https://doi.org/10.1104/pp.127.1.159.

Evans MD, M Dizdaroglu, and MS Cooke (2004) Oxidative DNA damage and disease: Induction, repair and significance. Mutat Research - Reviews in Mutation Research 567 (1): 1-61. http://doi.org/10.1016/j.mrrev.2003.11.001.

Faize M, L Burgos, L Faize, A Piqueras, E Nicolas, G Barba-Espin, MJ Clemente-Moreno, R Alcobendas, T Artlip, and JA Hernandez (2011) Involvement of cytosolic ascorbate peroxidase and $\mathrm{Cu} / \mathrm{Zn}$-superoxide dismutase for improved tolerance against drought stress. J Exp Bot. 62 (8): 2599-2613. http://doi.org/10.1093/jxb/erq432.

Foyer CH, H Lopez-Delgado, JF Dat, and IM Scott (1997) Hydrogen peroxide- and glutathione-associated mechanisms of acclimatory stress tolerance and signalling. Physiologia Plantarum 100 (2): 241-254. http://doi.org/10.1034/j.13993054.1997.1000205.x.

Heyno E, V Mary, P Schopfer, and A Krieger-Liszkay (2011) Oxygen activation at the plasma membrane: Relation between superoxide and hydroxyl radical production by isolated membranes. Planta 234: 35-45. http://doi.or/10.1007/s00425011-1379-y. 
Hu WH, XS Song, K Shi, XJ Xia, YH Zhou, and JQ Yu (2008) Changes in electron transport, superoxide dismutase and ascorbate peroxidase isoenzymes in chloroplasts and mitochondria of cucumber leaves as influenced by chilling. Photosynthetica 46 (4): 581-588. http://doi.org/10.1007/s11099-008-0098-5.

Kala SC (2015) Medicinal attributes on few species of oxalidaceae. International Journal of Phytopharmacy

Kampranis SC, R Damianova, M Atallah, G Toby, G Kondi, PN Tsichlis, and AM Makris (2000) A novel plant glutathione Stransferase/peroxidase suppresses Bax lethality in yeast. Journal of Biological Chemistry 275: 29207-29216. http://doi.org/10.1074/jbc.M002359200.

Lee YP, SH Kim, JW Bang, HS Lee, SS Kwak, and SY Kwon (2007) Enhanced tolerance to oxidative stress in transgenic tobacco plants expressing three antioxidant enzymes in chloroplasts. Plant Cell Reports 26: 591-598. http://doi.org/10.1007/s00299-006-0253-z.

Lelli JL, LL Becks, MI Dabrowska, and DB Hinshaw (1998) ATP converts necrosis to apoptosis in oxidant-injured endothelial cells. Free Radical Biology and Medicine 25 (6): 694-702. http://doi.org/10.1016/S0891-5849(98)00107-5.

Maheshwari R and RS Dubey (2009) Nickel-induced oxidative stress and the role of antioxidant defence in rice seedlings. Plant Growth Regulation 59: 37-49. http://doi.org/10.1007/s10725-009-9386-8.

Meriga B, BK Reddy, KR Rao, LA Reddy, and PBK Kishor (2004) Aluminium-induced production of oxygen radicals, lipid per- oxidation and DNA damage in seedlings of rice (Oryza sativa). J Plant Physiol. 161 (1): 63-68. http://doi.org/10.1078/01761617-01156.

Mishra S, AB Jha, and RS Dubey (2011) Arsenite treatment induces oxidative stress, upregulates antioxidant system, and causes phytochelatin synthesis in rice seedlings. Protoplasma 248: 565-577. http://doi.org/10.1007/s00709-010-0210-0.

Noctor G and CH Foyer (1998) Ascorbate and glutathione: Keeping Active Oxygen Under Control. Annual Review of Plant Physiology and Plant Molecular Biology 49: 249-279. http://doi.org/10.1146/annurev.arplant.49.1.249.

Sharma P, AB Jha, RS Dubey, and M Pessarakli (2012) Reactive oxygen species, oxidative damage, and antioxidative defense mechanism in plants under stressful conditions. Journal of Botany, Article ID 217037. http://doi.org/10.1155/2012/217037.

Valko M, H Morris, and MTD Cronin (2005) Metals, toxicity andoxidative stress. Curr. Med. Chem.,12, 1161-1208. http://doi.org/10.2174/0929867053764635.

Verma S and RS Dubey (2003) Lead toxicity induces lipid peroxidation and alters the activities of antioxidant enzymes in growing rice plants. Plant Science 164 (4): 645-655. http://doi.org/10.1016/S0168-9452(03)00022-0.

Yan J, N Tsuichihara, T Etoh, and S Iwai (2007) Reactive oxygen species and nitric oxide are involved in ABA inhibition of stomatal opening. Plant, Cell and Environment 30 (10): 13201325. http://doi.org/10.1111/j.1365-3040.2007.01711.x. 